\title{
Introducing a new section in the International Journal of Life Cycle Assessment: Critical Review and Life Cycle Assessment Standards
}

\author{
Walter Klöpffer ${ }^{1}$ (1)
}

Received: 12 March 2017 / Accepted: 23 April 2017 / Published online: 17 May 2017

(C) Springer-Verlag Berlin Heidelberg 2017

The Editors of the International Journal of Life Cycle Assessment created a new section called "Critical Review and Life Cycle Assessment Standards". As the subject editor for this new article type, I bring much experience as a critical reviewer, having served in the roles of review panel leader, copanellist and individual expert. My earliest experience goes back to the Sesimbra workshop on Life Cycle Assessment (LCA) code of practice (SETAC 1993). Furthermore, as member of the German expert group advising the German members of the ISO 14040ff standards, I was responsible for checking the translation (so also responsible for keeping the old German name for LCA: Ökobilanz). I published several papers on the critical review process and the "magical" critical review triangle which includes the Commissioner, Practitioner and Critical review panel (Klöpffer 2012).

LCA developed out of modest origins in the 1980s and soon developed into a popular method for environmental comparisons on the basis of functional unit and cradle-to-grave system boundaries. Since there was no description of the method, contradictory results and claims for environmental superiority of some product systems occurred. In this situation, the Society of Environmental Toxicology and Chemistry (SETAC) took the lead with a series of international workshops, culminating in a first set of rules, or code of practice (SETAC 1993). Soon thereafter, the International Standards Organisation (ISO) started its activities with the same aim, but with a much broader basis, and

Responsible editor: Mary Ann Curran

Walter Klöpffer

walter.kloepffer@t-online.de

1 LCA Consult \& Review, Am Dachsberg 56E, 60435 Frankfurt am Main, Germany published four international standards covering the whole method (ISO 1997-2000; Finkbeiner 2014):

- $\quad$ Principles and framework (ISO 14040:1997, 2006)

- Goal and scope definition and inventory analysis (ISO 14041:1998)

- Life cycle impact assessment (ISO 14042:2000)

- Life cycle interpretation (ISO 14043:2000)

The ISO series of LCA-based standards was modified only once (Finkbeiner et al. 2006) into ISO 14040:2006 and ISO 14044:2006. The first standard contains all general statements, such as the structure shown above and how an LCA study should be performed. In ISO, the use of the word "shall" indicates mandatory statements that have to be followed without exception. The only "shall" in ISO 14040:2006 is in the statement that the evaluation shall be performed according to 14044:2006. In this way, studies performed "in the spirit of ISO" cannot be claimed as performed "according to" ISO. In this standard, all strict statements including the critical review are necessary if "comparative assertions" are deduced from the first three items listed above. A statement saying that one of the alternative systems studied is better or at least equal to another system - under environmental aspects - has to be confirmed very strictly in order to be acceptable.

Here comes a key-element of ISO-LCA: the critical review must be performed by experts not involved in the actual study. If no "comparative assertion" is made, a review by one independent expert is sufficient. If, however, comparative assertions are made, a critical review panel of at least three experts including the chair has to check the whole LCA study and write a review report. This can be done after completion of the study, or preferably accompanying, so that improvements suggested by the review panel can be taken into account by the studyperformers (practitioners) (Klöpffer 2005, 2012) (ISO TS 
2014). The accompanying critical review is in general more expensive due to the need for more frequent panel meetings, etc. The time demand can often be kept comparable to reviews done "a posteriori". The results of the critical reviews have to be made open to the public, at least upon request.

Depending on confidential product details it may contain, the entire study including the findings of the critical review is often not fully published and made publicly available. This brings us to the core of this editorial which tries to join the critical review process with the standards edited by ISO, and other organisations not mentioned here. Publishing critical reviews (outside the LCA studies to which they belong) has never been popular. As a result, LCA practitioners are often not aware what is expected from them during the review process or if they are invited to review. Here, the new ISO technical specification (TS) 14071 (2014) will certainly be helpful. Experience obtained with this document would be welcome to the whole LCA community. Furthermore, although the ISO standards are the most important ones and have a global reach, there are other life cycle standards which are regionally more restricted or contain only one impact category (mostly "global warming") or refer to only one product group. Such studies are often called "footprints" and may contain important information with regard to the products and/or impacts they refer to. A comparative assertion about the relative environmental impacts of product systems is not possible in such case. The relevant standards should nevertheless be studied and the limits of the method explored and published in a peer-reviewed journal.

Following the normal route for submissions, papers submitted to the journal via Springer's website under the new article type "Critical Review and LCA Standards" will be sent automatically to the editor-in-chief and from there to me. To assist in the review process, people with experience in critical review and LCA standards are kindly invited to provide me with their "coordinates" and a short CV for potential submission reviews. Anticipated submissions may cover the announcement of new LCA standards, when that occurs, of course. Problems frequently encountered during the critical review process and how to avoid them could also be a topic.

I look forward to good cooperation within the LCA community for improving the quality of both the use of the standards and the LCA review process.

\section{References}

Finkbeiner M, Inaba A, Tan RBH, Christiansen K, Klüppel H-J (2006) The new international standards for life cycle assessment ISO 14040 and ISO 14044. Int J Life Cycle Assess 11(2):80-85

Finkbeiner M (2014) The international standards as the constitution of life cycle assessment: the ISO 14040 series and its offsprings. LCA Compendium-The Complete World of Life Cycle Assessment. Klöpffer, W. (ed.), Springer, Dordrecht (2014)

ISO 14040 (1997) Environmental management—-life cycle assessmentprinciples and framework, Geneva

ISO 14041 (1998) Environmental management—life cycle assessmentgoal and scope definition and inventory analysis, Geneva

ISO 14042 (2000) Environmental management—-life cycle assessmentlife cycle impact assessment, Geneva

ISO 14043 (2000) Environmental management—life cycle assessmentlife cycle interpretation, Geneva

ISO 14040 (2006) Environmental management—-life cycle assessmentprinciples and framework, Geneva

ISO 14044 (2006) Environmental management—life cycle assessmentrequirements and guidelines, Geneva

ISO TS 14071 (2014) Environmental management-life cycle assessment-requirements and guidelines for critical review processes and reviewer competencies, Geneva

Klöpffer W (2005) The critical review process according to ISO 14040 43: an analysis of the standards and experiences gained in their application. Int J Life Cycle Assess 10(2):98-102

Klöpffer W (2012) The critical review of life cycle assessment studies according to ISO 14040 and 14044: origin, purpose and practical performance. Int J Life Cycle Assess 17(9):1087-1093

SETAC-Society of Environmental Toxicology and Chemistry (1993) Guidelines for life-cycle assessment: a "Code of Practice". From the SETAC Workshop held at Sesimbra, Portugal, 31 March - 3 April 1993, $1^{\text {st }}$ edition. Brussels and Pensacola 1993 